\title{
The Structural Equation Model of Intention to Discontinue Drinking Highly Caffeinated Beverage of Undergraduate Students
}

\author{
Kyu Eun Lee ${ }^{1}$, Yunsoo Kim ${ }^{2}$ \\ ${ }^{1}$ Professor, Department of Nursing, Catholic Kwandong University, Gangneung; ${ }^{2}$ Assistant Professor, Department of Nursing, Catholic Kwandong University, \\ Gangneung, Korea
}

Purpose: The purpose of this study was to test a model for intention to discontinuation drinking high caffeinated beverages among undergraduate students. This model was based on the Ajzen's theory of planned behavior and Becker's health belief model. Methods: Participants consisted of 201 undergraduate students. Data were collected by questionnaires from March 11 to May 24, 2019. Collected data were analyzed using SPSS/WIN 22.0, AMOS 22.0 program. Results: The assessment of the model indicated an acceptable fit (normed $x^{2}=1.65$, goodness-of-fit index $[\mathrm{GFI}]=.83$, adjusted GFI=.79, comparative fit index $[\mathrm{CFI}]=.92$, standardized root mean square residual $[S R M R]=.05$, Tucker-Lewis index $[\mathrm{TLI}]=.91$, normed fit index $[\mathrm{NFI}]=.87$, root mean square error of approximation [RMSEA] =.07). Perceived behavior control, subjective norm, the subjective attitude was found to have a significant direct effect on the intention to discontinuation of drinking a high caffeinated beverage. The variances of this model explained $45.3 \%$ of the variance in intention to discontinuation of drinking a high caffeinated beverage. Conclusion: These results suggest that a need to increase awareness of adverse effects and potential risks of high caffeinated beverage consumption in undergraduate students. Besides, the university and government should provide education and campaigns to prevent excessive high-caffeinated beverage consumption.

Key words: Energy drinks; Intention; Attitude; Behavior control; Structural equation modeling

\section{Corresponding author Yunsoo Kim \\ https://orcid.org/0000-0002-1788-563X}

Department of Nursing, The Catholic Kwandong University, 24 Beomil-ro, 579 Beon-gil, Gangneung 25601, Korea

TEL +82-33-649-7614 FAX +82-33-649-7610

E-MAIL doxapram@naver.com

Received Sep 1, 2019 Revised Nov 8, 2019 Accepted Nov 26, 2019 (a) This is an Open Access article distributed under the terms of the Creative Commons Attribution NonCommercial License (http://creativecommons.org/licenses/by-nc/4.0/) which permits unrestricted noncommercial use, distribution, and reproduction in any medium, provided the original work is properly cited.

\section{INTRODUCTION}

\section{Need for Study}

Recent improvements in living standards and advances in food processing technologies have been accompanied by increasing demand and consumption of various kinds of prepared foods. Of particular note, highly caffeinated energy drinks have become very popular among teenagers, college students, and office workers [1]. These products, some of which are marketed in Korea (such as Red Bull, Nalu, Burn, and Monster), contain up to 207 milligrams of caffeine in each can. Highly caffeinated drinks are purported not only to quench thirst and to be flavorful, but also to relieve fatigue and to cause both mental and physical arousal [2,3]. College students often try to stay awake for long periods of time in efforts to earn high grades because of the pressure associated with future employment [2,4], and they also frequently mix these drinks with other caffeinated drinks (and even alcoholic beverages) to obtain stronger effects. A survey conducted by the Korea Consumer Agency (2013) showed that 88.7\% of college students had tried energy drinks, which was higher than the corresponding percentages of middle-school and high- 
school students, and that $49.3 \%$ of students had tried mixing energy drinks with alcohol [5].

Highly caffeinated drinks are known to enhance concentration, endurance, and performance [6], but excessive consumption may lead to hypersensitivity, overexcitement, and insomnia via the effects of these drinks on the central nervous system, as well as adverse effects on the stomach, intestine, colon, and endocrine systems [4]. In particular, the excessive intake of highly caffeinated drinks by teenagers has been reported as a potential cause of both physical health problems (e.g., heart problems) and mental problems (e.g., attention deficit hyperactivity disorder) [1,4,7].

Due to the problems posed by consuming highly caffeinated drinks, the Ministry of Food and Drug Safety [5] has mandated that warning labels be placed on these beverages cautioning against consumption by children, pregnant women, and those who are sensitive to caffeine, and has set the recommended amount of adult caffeine intake as less than 400 $\mathrm{mg}$ daily. Since the caffeine content of energy drinks sold in Korea ranges from 30 to $207 \mathrm{mg}$ per can [8], drinking two cans of a highly-caffeinated drink or consuming other caffeinated drinks can easily cause an individual to exceed the recommended amount of daily caffeine intake. Therefore, measures should be devised to improve awareness of excessive caffeine intake.

Various theoretical approaches have been developed to predict human health behaviors, including the health belief model and the theory of planned behavior. The theory of planned behavior was developed by Ajzen in 1991 on the basis of the theory of reasoned action and has subsequently been used to explain various behaviors [9]. The theory of planned behavior also includes perceived behavioral control as a way to account for human behaviors that cannot be controlled with an individual's will, with a particular focus on intention as a direct determinant of behavior, suggesting that intentions precede actions. In this framework, attitudes toward a behavior, subjective norms, and perceived behavioral control are seen as determinants of intention to engage in the behavior $[9,10]$. According to this theory, people are more likely to transform their thoughts into action if they think that their health actions produce value-creating results, that they need to carry out a certain action if they value themselves, and that they have the ability and opportunity to execute the action [11]. Since intention is a significant predictor of behavior and perceived behavioral control can significantly explain high caffeine consumption [12], encouraging the intention to stop consuming highly caffeinated drinks is expected to lead to an increase in the actual discontinuation of highly caffeinated drink consumption. However, there are limits to the degree to which intention can be explained only in terms of the basic variables of the theory of planned behavior since the factors that govern human behavior in relation to intention are influenced by various environmental and psychological causes.

The health belief model [13], developed by Becker, is widely used to predict health behavior based on behavioral appraisals associated with perceived risks to which individuals are exposed. The health belief model suggests that health beliefs refer to subjective perceptions of a person's health behavior, and can be divided into perceived threats (based on a combination of susceptibility and severity) and behavioral assessments (perceived benefits and perceived barriers) regarding diseases. Recent studies using the health belief model have reported that health beliefs affect health prevention behaviors or intention to engage in health behaviors [14,15].

Previous studies of highly caffeinated beverages have primarily focused on studying demographic factors related to high caffeine intake and the physiological and psychological effects of their consumption [4,7,16-18]. However, studies on socio-psychological factors that influence college students' high-caffeine intake are rare, and no study has yet explored factors that affect the discontinuation of highly caffeinated beverage consumption. Due to stress from academics and uncertainty regarding their career path, many college students consume highly caffeinated drinks in anticipation of positive effects such as enhanced performance through increased alertness [2,4,6], but instead suffer from undesired results of caffeine dependence, such as withdrawal, addiction, and sleep disorders $[17,18]$. Early adulthood, of which the time spent in college is a part, is an important period in which habits are established that persist for the rest of the lifetime. Therefore, forming good habits in terms of caffeine consumption during this period could serve as a foundation for improving the health of university students and enabling them to reach their maximum health potential in adulthood.

In light of these considerations, by applying the theory of planned behavior and the health belief model, we sought to identify the crucial variables that influence undergraduate students' intention to stop consuming highly caffeinated drinks, to characterize the relationships between highly caffeinated drink consumption and related variables, and to explain the extent to which these variables influence intention to discontinue highly caffeinated beverage consumption. By doing so, we hope to provide a basic reference for guiding college students to engage in appropriate consumption of highly caffeinated beverages.

\section{Purpose}

The purpose of this study was to establish a hypothetical model of the factors influencing college students' intention to 
stop drinking highly caffeinated beverages based on Ajzen's theory of planned behavior [9] and Becker's health belief model [13], to identify the causal relationships among these factors, and then finally to test the model fit.

\section{Theoretical Framework and Hypothetical Model}

Our paper builds on the prior work by Ajzen [9] and Becker [13]. Furthermore, we established a theoretical framework of the relationships among the relevant factors based on the prior literature investigating college students' intention to cease high caffeine intake. Our hypothetical model of the intention to stop high caffeine consumption consisted of two exogenous variables (perceived benefits, perceived barriers) and four endogenous variables (subjective attitudes, subjective norms, subjective behavioral control, and intention to discontinue).

Perceived benefits and perceived barriers affect subjective attitudes towards the intention to stop high caffeine intake, and subjective attitudes in turn affect the intention. Perceived benefits and perceived barriers of high caffeine intake affect subjective norms, which again affect the intention to discontinue high caffeine intake. The perceived benefits and perceived barriers of high caffeine intake affect perceived behavioral control, which affects the intention to stop high caffeine intake. A hypothetical path constructed on this basis is shown in Figure 1.

\section{METHODS}

\section{Study Design}

Based on the theory of planned behavior and health belief model, this study identified causal relationships among factors influencing college students' intention to stop drinking highly caffeinated beverages, established a hypothetical model, and tested the hypothesis and the suitability of a structural equation model.

\section{Participants}

The participants of this study were 201 university students from five cities and provinces (Seoul, Gyeonggi, Gangwon, South Chungcheong, and South Gyeongsang Provinces). First, students from each location were randomly selected. We surveyed 405 students who had agreed to participate after receiving an explanation of the purpose of the study and selected 201 students who were suitable for the purposes of the study. Those who met at least one of the following three criteria were selected as participants: 1 ) having consumed highly caffeinated drinks in the past week, 2) consuming at least four caffeinated drinks daily, 3) responding that they were addicted to caffeine.

The number of participants in this study was based on the maximum likelihood method of selecting a sample size in a

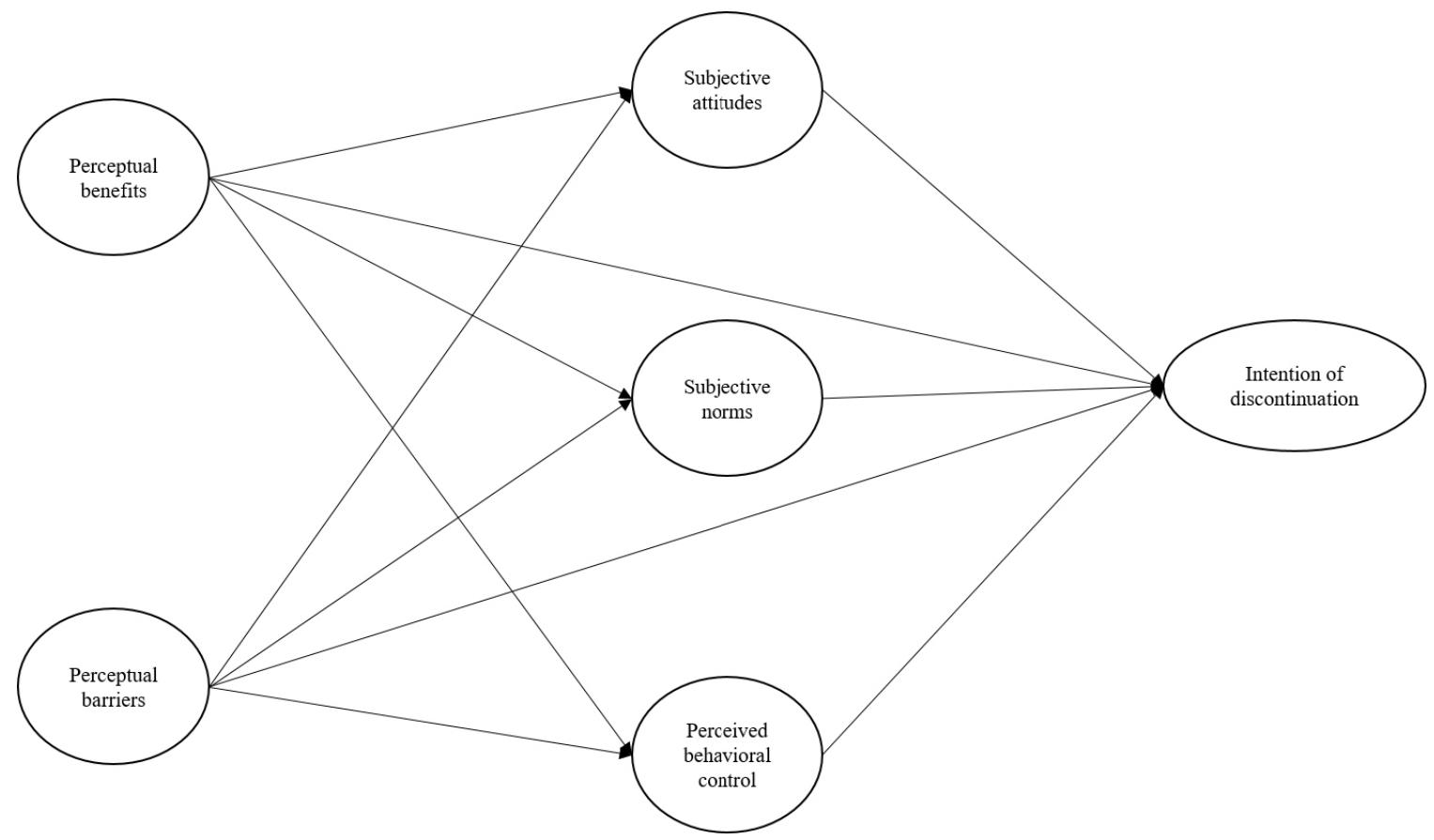

Figure 1. Hypothetical model. 
structural equation model, and 405 responses were first solicited in consideration of the exclusion rate because the data satisfied multivariate normality. Finally, 201 responses were selected and the remaining 204 were excluded because the responses were inappropriate or the respondents did not report high caffeine intake. Although scholars have expressed various opinions regarding appropriate sample sizes, a sample of 201 participants was deemed to be an appropriate number for this study according to evidence suggesting that an appropriate sample size is $150 \sim 400$ on the basis of a classification of five factors that may influence the sample size $[19,20]$.

\section{Measurements}

We removed items with an average variance extracted (AVE) below .50 in confirmatory factor analysis (CFA) and then conducted the analysis. The final items included the general characteristics of the study participants, five items on perceived benefits, three items on perceived barriers, seven items on subjective attitudes, and four items on the intention to stop drinking highly caffeinated beverages. We followed the survey method described by Ajzen [9] and gathered information on subjective attitudes towards stopping high caffeine intake, subjective norms, perceived behavioral control, and the intention to stop high caffeine intake. Then, two professors in charge of postgraduate nursing research methodology confirmed the content validity of the items after two researchers had modified and revised the method to fit the purpose of the study.

\section{1) General characteristics}

The general characteristics of the participants included age, grade, gender, and pattern of high caffeine intake, which consisted of the amount of caffeine consumed in the past week, the timing and place of highly caffeinated drink consumption, the presence and symptoms of side effects from high caffeine intake, and the reason why respondents perceived themselves to be caffeine addicts.

\section{2) Perceived benefits}

Perceived benefits refer to individuals' beliefs that certain actions are beneficial for preventing them from developing a disease [13]. This study measured perceived benefits through five binary-scale items on perceived benefits from the Caffeine Belief Scale developed by McIlvain, Noland, and Bickel [21], which is based on Becker's health belief model. Each item is given a response of 'yes' ( 1 point) or 'no' (0 points), with higher scores corresponding to more perceived benefits from consuming caffeine. The Kuder Richardson-20 (KR-20) confidence level of this scale in this study was .74.

\section{3) Perceived barriers}

Perceived barriers refer to the degree to which individuals perceive negative factors that prevent them from implementing disease prevention actions [13]. This study measured perceived barrier through three binary-scale items on perceived barriers from the Caffeine Belief Scale developed by McIlvain et al. [21], which is based on Becker's health belief model. The response to each item is 'yes' ( 1 point) or 'no' ( 0 points), and higher scores indicate that an individual experiences more side effects from consuming caffeinated drinks. The KR-20 confidence level of this scale in this study was .74.

\section{4) Subjective attitudes}

Attitudes refer to the degree to which an individual positively or negatively evaluates the performance of a particular action [9], which in this study meant positive or negative assessments of discontinuing highly caffeinated drink consumption. To evaluate attitudes, the following eight semantic differential scales were used: Stopping the consumption of highly caffeinated drinks is desirable/undesirable, important/ unimportant, optional/mandatory, unrealistic/realistic, harmful/beneficial, hard/easy, stupid/wise, and joyless/joyful.

After removing one of the items (optional/mandatory), for which an AVE of less than or equal to .50 was found in CFA, the remaining seven items were used. On the attitude measurement tool, 1 to 7 points were assigned to each pair of adjectives representing an individual's assessment of an action. Attitudes were represented by the sum of the seven items, with the total score ranging from 7 to 49 points. Cronbach's $\alpha$ for this tool was .85 in this study.

\section{5) Subjective norm}

Subjective norms refer to the degree to which individuals subjectively perceive social pressure to perform certain actions [9]. In this study, subjective norms referred to the degree to which subjects were aware of pressure from others to discontinue high caffeine intake. Subjective norms were measured on a 7-point scale containing three items. Each item received a response ranging from 'strongly disagree' (1 point) to 'strongly agree' (7 points), with higher scores corresponding to stronger subjective norms for stopping high caffeine intake. Cronbach's $\alpha$ for this tool was .90 in this study.

\section{6) Perceived behavioral control}

Perceived behavioral control refers to the degree of difficulty that individuals perceive in certain actions. In this study, it referred to the degree of difficulty that individuals perceived in discontinuing highly caffeinated drink consumption [9]. Perceived behavioral control was measured on a 7-point scale with five items. Each item received a response of 'strong- 
ly disagree' (1 point) to 'strongly agree' (7 points), with higher scores corresponding to greater perceived ease of discontinuing high caffeine intake. Cronbach's $\alpha$ for this tool was .89 in this study.

\section{7) Intention to stop}

Intention refers to the degree to which an individual intends to perform a specific action [9], and in this study, it referred to how voluntarily the subject would work to stop consuming highly caffeinated drinks and how much effort they would make to do so within the next 2 weeks. Intention was measured on a 7-point scale with four items. Each item received a response ranging from 'strongly disagree' (1 point) to 'strongly agree' (7 points), with higher scores indicating a stronger intention of stopping caffeine intake. Cronbach's $\alpha$ for this tool was .88 in this study.

\section{Data Collection and Ethical Concerns}

Data were collected from March 11, 2019 to May 24, 2019 after obtaining approval from the Institutional Life Research Ethics Committee (CKU-19-01-0101). In total, 410 university students who expressed their intention to participate in the study signed written consent forms and were given instructions on how to participate after receiving an explanation about the purpose and confidentiality of the study, the anonymity of the research, the academic purposes of data collection, and their ability to refuse to participate or withdraw from the study without any disadvantages. The time required to complete the survey was 10 15 minutes and small rewards were provided for the participants. Of the 410 surveys, 405 were returned and 201 of the responses (from individuals with high caffeine intake) were used for the final data analysis.

\section{Data Analysis}

The collected data were analyzed using SPSS for Windows version 22.0 and AMOS version 22.0 (IBM Corp., Armonk, NY, USA). The variables related to participants' general characteristics were analyzed in terms of frequency, percentage, mean, and standard deviation as descriptive statistics.

The multivariate normality of the sample was verified by mean values, standard deviation, skewness, and kurtosis using SPSS for Windows version 22.0. The model fit was validated using AMOS version 22.0. Model fit was tested using the $x^{2}$ test (CMIN), normed $x^{2}$ test (CMIN/df), goodness-offit index (GFI), adjusted goodness of fit index (AGFI), comparative fit index (CFI), a non-normed fit index (Tucker-Lewis index; TLI), normed fit index (NFI), standardized root mean square residual (SRMR), and root mean square error of ap- proximation (RMSEA). The significance of the estimated coefficient for each path in the hypothetical model was analyzed through the critical ratio and $p$-value $(p<.050)$. To verify the statistical significance of the direct, indirect, and total effects of the hypothetical model, the bootstrapping method was used.

\section{RESULTS}

\section{General Characteristics of the Participants}

The general characteristics of the study participants are shown in Table 1. In total, 201 participants were eligible for the study. Their average age was 22.2 years, $45.3 \%$ were sophomores, and $52.2 \%$ were women. The average number of caffeinated drinks consumed was 3.44, and the average number of highly caffeinated drinks consumed was 1.57 weekly. Libraries were the location of consumption for $36.3 \%$ of the participants, and $41.8 \%$ of the participants consumed caffeine before and after studying. Side effects of caffeine intake were reported by $39.3 \%$ of participants, including sleep disorders (36.8\%) and heart palpitations (34.9\%). The reasons for considering themselves to be caffeine-addicted were that they consumed caffeine at least once a day $(43.8 \%)$, relied on $(31.8 \%)$, felt anxious about not consuming caffeine (14.9\%), and others $(10.5 \%)$.

\section{Descriptive Statistics and Confirmatory Factor Analysis}

The mean score for the perceived benefits of high caffeine intake was 2.40, the mean score for perceived barriers was 1.87 , the mean score for subjective attitudes was 29.46 , the mean score for subjective norms was 3.53 , the mean score for perceived behavioral control was 4.28 , and the mean score for intention to stop was 3.29. Single-variable normality testing yielded skewness of -0.51 to 0.50 and kurtosis of -0.97 to 0.89 . Since the absolute values of skewness and kurtosis were distributed between -2 and +2 , the conditions of single-variable normality were met. CFA was conducted to assess the validity of normality, and demonstrated that the normalized standard factor loading was above the baseline value $(\lambda>.50)$, the construct validity was above .80 , and the AVE was above .50 , indicating that there was no issue with convergent validity. We further examined the correlations between the correlation matrix and the AVE to verify discriminant validity. The correlation coefficients ranged between .07 and .53 , with absolute values are less than .85 (Table 2).

\section{Goodness-of-fit Testing of the Model}

Prior to analyzing the hypothetical model, we conducted 
Table 1. General Characteristics of Participants

$(N=201)$

\begin{tabular}{|c|c|c|}
\hline Characteristics & Categories & $\mathrm{n}(\%)$ or $\mathrm{M} \pm \mathrm{SD}$ \\
\hline Age (year) & & $22.2 \pm 13.1$ \\
\hline \multirow[t]{4}{*}{ Year in college } & Freshman & $44(21.9)$ \\
\hline & Sophomore & $91(45.3)$ \\
\hline & Junior & $35(17.4)$ \\
\hline & Senior & $31(15.4)$ \\
\hline \multirow[t]{2}{*}{ Sex } & Male & $96(47.8)$ \\
\hline & Female & $105(52.2)$ \\
\hline Caffeinated beverage intake per week (cups) & & $3.44 \pm 2.55$ \\
\hline Highly caffeinated beverage intake per week (cans) & & $1.57 \pm 2.08$ \\
\hline \multirow[t]{3}{*}{ Time of caffeine consumption } & Before and after studying & $84(41.8)$ \\
\hline & When feeling drowsy & $56(27.9)$ \\
\hline & Before and after meals & $61(30.3)$ \\
\hline \multirow[t]{5}{*}{ Location of caffeine consumption } & Library & $73(36.3)$ \\
\hline & House & 63 (31.3) \\
\hline & Classroom & 35 (17.5) \\
\hline & Bar & $5(2.5)$ \\
\hline & Others & $25(12.4)$ \\
\hline \multirow[t]{2}{*}{ Adverse experience with caffeine intake } & Yes & 79 (39.3) \\
\hline & No & $122(60.7)$ \\
\hline \multirow[t]{5}{*}{ Symptoms of adverse effects* $(n=79)$} & Sleeplessness & $39(49.4)$ \\
\hline & Palpitation & 37 (46.8) \\
\hline & Skin roughness & $14(17.7)$ \\
\hline & Anxiety & $10(1.7)$ \\
\hline & Others & $6(7.6)$ \\
\hline \multirow[t]{4}{*}{ Reasons for considering oneself a caffeine addict } & I consume it at least once a day & $86(42.8)$ \\
\hline & I rely on caffeinated beverages & $64(31.8)$ \\
\hline & If I don't drink caffeinated beverages, I become nervous & $30(14.9)$ \\
\hline & Others & 21 (10.5) \\
\hline
\end{tabular}

*Duplicate responses.

goodness-of-fit testing without modifying model. Because CFA confirmed the suitability of the model that included measurements of subjective attitudes, subjective norms, and perceived behavioral control over the discontinuation of highcaffeine intake. The following values were obtained from goodness-of-fit testing: $x^{2}=296.61$, normed $x^{2}=1.65, \mathrm{GFI}=.83$, $\mathrm{AGFI}=.79, \mathrm{CFI}=.92, \mathrm{SRMR}=.05, \mathrm{TLI}=.91, \mathrm{NFI}=.87$, and $\mathrm{RMSEA}$ $=.07$. Initially, it appeared that the hypothetical model would be rejected, as $x^{2}=296.61(p<.001)$, but we also utilized the normed $x^{2}\left(x^{2} / \mathrm{df}\right)$ as a measure that is less sensitive to sample size than $x^{2}[19,20]$. The normed $x^{2}$ was found to be 1.65 , where a value less than 2 indicates a good fit. The GFI, CFI, SRMR, and TLI also showed robust results. Although the values of RMSEA (.07) and NFI (.87) were not consistent with goodness-of-fit criteria, they tend to decrease when a weak causal relationship is inserted into a model because the AGFI adjusts the values of the GFI to account for the simplified nature of the model. In addition, research has shown that the AGFI does not produce robust results [22], and studies in recent years have tended not to report the AGFI. Values of RMSEA $<.05$ indicate that a model is suitable, and values within the range of .05 to .08 are considered to be acceptable. Therefore, the goodness of fit of this model can be assessed as acceptable [22].

\section{Analysis of the Hypothetical Model}

The results of the analysis of college students' intention to stop drinking highly caffeinated drinks are shown in Table 3 and Figure 2. The scores for subjective norms relating to high caffeine intake increased as scores for perceived barriers increased $(\beta=.13, p=.046)$, and the scores for perceived behav- 
Table 2. Descriptive Statistics of Observed Variables

$(N=201)$

\begin{tabular}{|c|c|c|c|c|c|c|c|c|}
\hline Characteristics & $\mathrm{M} \pm \mathrm{SD}$ & MR & Skewness & Kurtosis & SE & Estimate & $\mathrm{CR}$ & $p$ \\
\hline Perceptual benefits & $2.40 \pm 1.45$ & 5.00 & 0.06 & -0.80 & 0.83 & - & - & - \\
\hline Perceptual barriers & $1.87 \pm 0.94$ & 3.00 & -0.51 & -0.59 & 1.00 & - & - & - \\
\hline Subjective attitudes & $29.46 \pm 7.49$ & 42.00 & 0.14 & 0.89 & & & & \\
\hline Undesirable - desirable & $4.27 \pm 1.49$ & 6.00 & -0.13 & -0.40 & 1.00 & - & - & - \\
\hline Unimportant - important & $4.16 \pm 1.51$ & 6.00 & -0.09 & -0.24 & 0.84 & 0.12 & 7.01 & $<.001$ \\
\hline Unrealistic - realistic & $3.94 \pm 1.39$ & 6.00 & -0.03 & 0.18 & 0.94 & 0.11 & 8.39 & $<.001$ \\
\hline Harmful - beneficial & $4.36 \pm 1.52$ & 6.00 & -0.06 & -0.57 & 1.00 & 0.12 & 8.15 & $<.001$ \\
\hline Hard - easy & $4.00 \pm 1.56$ & 6.00 & 0.03 & -0.50 & 1.02 & 0.13 & 8.14 & $<.001$ \\
\hline Stupid - wise & $4.44 \pm 1.36$ & 6.00 & -0.02 & -0.16 & 1.07 & 0.11 & 9.51 & $<.001$ \\
\hline Joyless - joyful & $4.30 \pm 1.44$ & 6.00 & -0.10 & 0.25 & 1.05 & 0.12 & 8.92 & $<.001$ \\
\hline Subjective norms & $3.53 \pm 1.54$ & 6.00 & 0.12 & -0.48 & & & & \\
\hline $\begin{array}{l}\text { Most people who are important to me think } \\
\text { I should not drink highly caffeinated } \\
\text { beverages within the next } 2 \text { weeks. }\end{array}$ & $3.22 \pm 1.74$ & 6.00 & 0.27 & -0.87 & 1.00 & - & - & - \\
\hline $\begin{array}{l}\text { Most people who are important to me are in } \\
\text { favor of me not drinking highly caffeinated } \\
\text { beverages within the next } 2 \text { weeks. }\end{array}$ & $3.76 \pm 1.64$ & 6.00 & -0.10 & -0.60 & 0.88 & 0.06 & 14.30 & $<.001$ \\
\hline $\begin{array}{l}\text { Most of the people who are important to } \\
\text { me hope I don't drink highly caffeinated } \\
\text { beverages within } 2 \text { weeks. }\end{array}$ & $3.62 \pm 1.70$ & 6.00 & -0.04 & -0.85 & 0.97 & 0.06 & 15.45 & $<.001$ \\
\hline Perceived behavioral control & $4.28 \pm 1.53$ & 5.60 & 0.12 & -0.84 & & & & \\
\hline It is difficult to control. & $4.18 \pm 1.92$ & 6.00 & 0.03 & -1.21 & 0.79 & 0.09 & 9.28 & $<.001$ \\
\hline It is manageable. & $4.22 \pm 1.90$ & 6.00 & -0.06 & -1.13 & 1.00 & - & - & - \\
\hline It is easy to control. & $4.92 \pm 1.65$ & 6.00 & -0.51 & -0.69 & 0.70 & 0.07 & 9.52 & $<.001$ \\
\hline I can control it through my will. & $4.04 \pm 1.87$ & 6.00 & 0.04 & -1.14 & 1.21 & 0.07 & 16.60 & $<.001$ \\
\hline It depends on what I do. & $4.03 \pm 1.90$ & 6.00 & -0.03 & -1.09 & 1.22 & 0.07 & 16.48 & $<.001$ \\
\hline Intention to stop & $3.29 \pm 1.70$ & 6.00 & 0.31 & -0.76 & & & & \\
\hline $\begin{array}{l}\text { I plan to stop drinking highly caffeinated } \\
\text { beverages. }\end{array}$ & $3.42 \pm 1.83$ & 6.00 & 0.26 & -0.92 & 1.00 & - & - & - \\
\hline $\begin{array}{l}\text { I will do my best to stop drinking highly } \\
\text { caffeinated beverages. }\end{array}$ & $3.49 \pm 1.83$ & 6.00 & 0.23 & -0.97 & 1.12 & 0.03 & 35.71 & $<.001$ \\
\hline $\begin{array}{l}\text { I will aim to stop drinking highly caffeinated } \\
\text { beverages. }\end{array}$ & $3.24 \pm 1.78$ & 6.00 & 0.35 & -0.81 & 0.92 & 0.03 & 27.22 & $<.001$ \\
\hline $\begin{array}{l}\text { I will try to stop drinking highly caffeinated } \\
\text { beverages. }\end{array}$ & $3.02 \pm 1.79$ & 6.00 & 0.50 & -0.72 & 0.81 & 0.05 & 17.57 & $<.001$ \\
\hline
\end{tabular}

$\mathrm{MR}=$ Measurement range; $\mathrm{SE}=$ Standardized estimate; $\mathrm{CR}=\mathrm{Critical}$ ratio.

ioral control increased as perceived benefits decreased $(\beta=$ $-.13, p=.043)$ and perceived barriers increased $(\beta=.09, p=.034)$. The scores for intent of discontinuation increased with increasing scores for subjective attitudes $(\beta=.22, p=.031)$, subjective norms ( $\beta=.38, p=.004)$, and perceived behavioral con- trol $(\beta=.55, p=.004)$. The coefficient of determination was $45.3 \%$.

\section{DISCUSSION}

Based on Ajzen's theory of planned behavior [9] and 


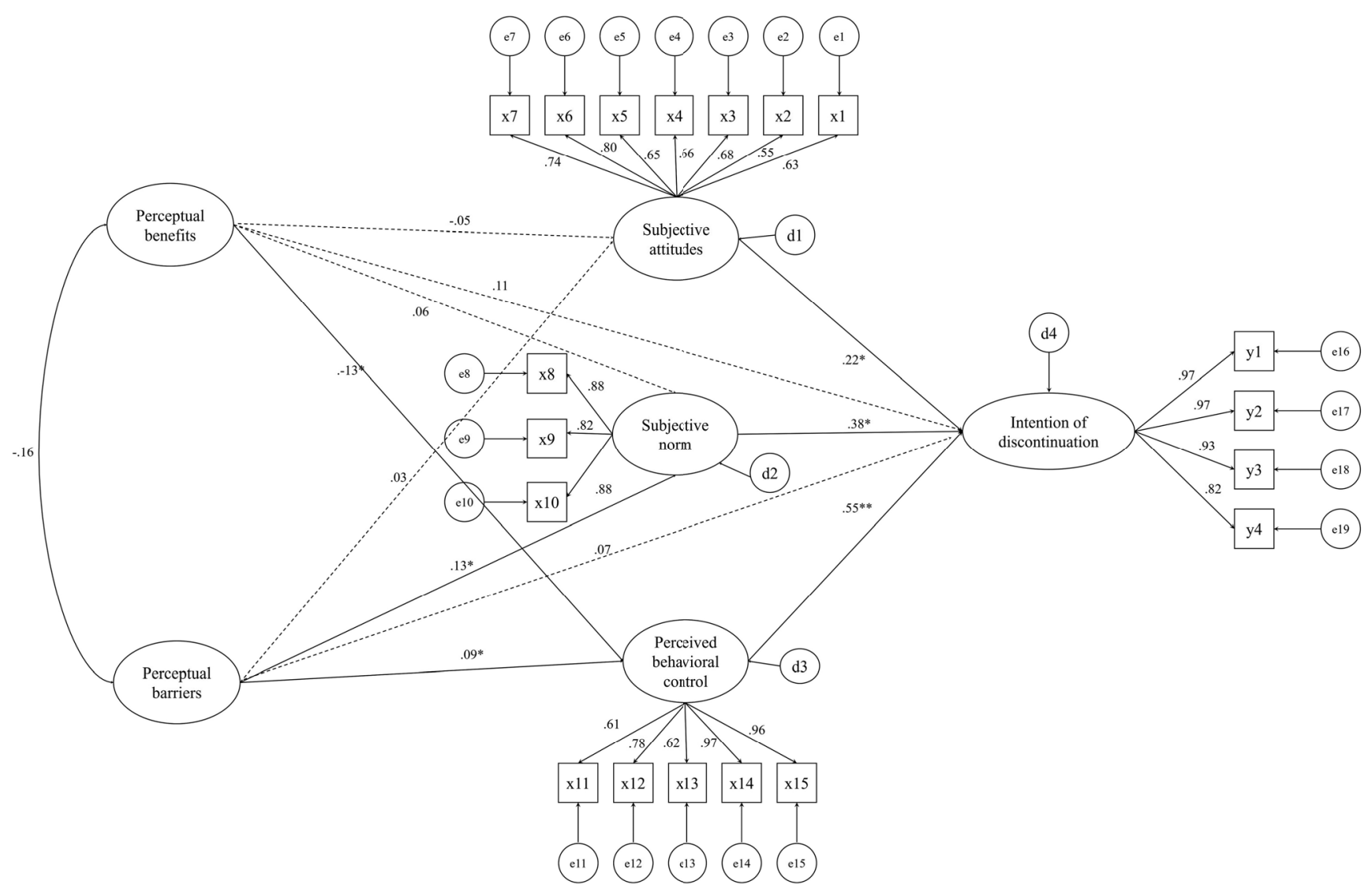

Figure 2. Effect analysis in the structural equation model.

Becker's health belief model [13], this study developed a hypothetical model describing intention to discontinue highly caffeinated drink consumption through a structural equation model within a theoretical framework of factors that influence the intention to stop high caffeine intake. In college students, perceived behavioral control, subjective norms, and subjective attitudes were shown have a direct effect on their intention to discontinue high levels of caffeine consumption. This is consistent with previous findings [23-25] that increased perceived behavioral control, subjective norms, and subjective attitudes all impacted intention to stop various behaviors.

These results show that perceived behavioral control over highly caffeinated beverage intake among college students had the most significant impact on their intention to discontinue consuming highly caffeinated beverages. Similar results were reported in a meta-analysis published in a major Korean academic journal [26], but distinct results were reported in a meta-analysis of reduced alcohol intake [27], a meta-analysis of health behaviors of young people in relation to nutrition [23], and a meta-analysis of health behaviors [25]. Perceived behavioral control refers to the perceived degree of difficulty in performing an action, which we believe reflects actual control. The present study found that college students' caffeine intake happened before and after studying (41.8\%), before and after meals (30.3\%), and when they felt drowsy (27.9\%); these are contexts that the participants judged as relatively easy for discontinuing highly caffeinated drink consumption, a logical leap from findings of certain locations of caffeine consumption to evidence of actual discontinuation.

This result supports previous findings that perceived behavioral control is affected by external control factors (e.g., time and opportunity) [28]. We propose that external control factors should be added to the perceived behavioral controls associated with high caffeine intake in future studies.

Subjective norms on highly caffeinated beverage intake were found to affect the intention to stop. The average score for subjective norms perceived by the subjects of this study was 3.53 points, and the average score for the item asking whether people who are close to the subjects were in favor of them stopping caffeine consumption within the next 2 weeks was 3.76, indicating that respondents felt particularly strong social pressure from certain people. Respondents with higher scores for subjective norms were more likely to intend to dis- 
Table 3. Model Fit, Estimates, and Standardized Effects of the Model

$(N=201)$

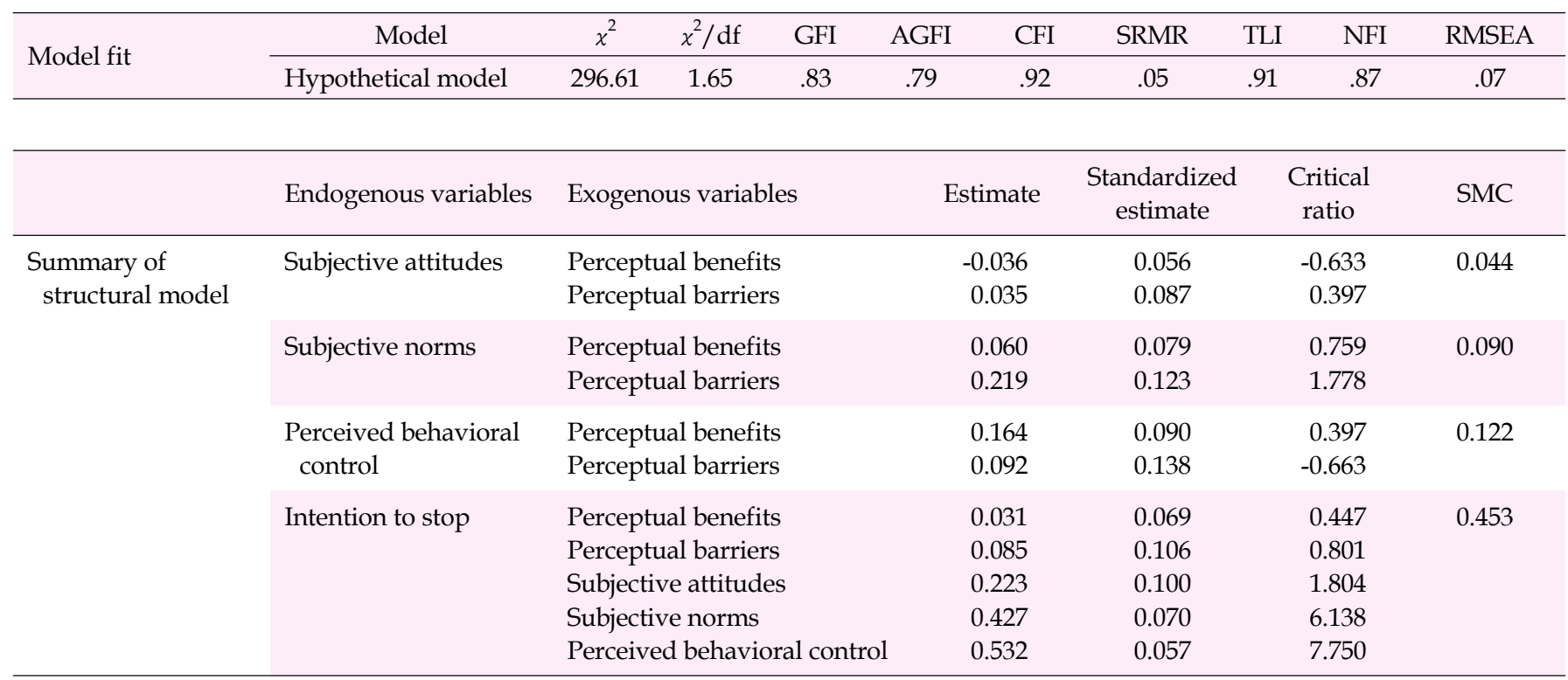

\begin{tabular}{|c|c|c|c|c|c|c|c|c|}
\hline & \multirow{2}{*}{ Endogenous variables } & \multirow{2}{*}{ Exogenous variables } & \multicolumn{2}{|c|}{ Direct effect } & \multicolumn{2}{|c|}{ Indirect effect } & \multicolumn{2}{|c|}{ Total effect } \\
\hline & & & B & $p$ & B & $p$ & B & $p$ \\
\hline \multirow{11}{*}{$\begin{array}{l}\text { Direct, indirect, and } \\
\text { total effects in the } \\
\text { model }\end{array}$} & \multirow{2}{*}{ Subjective attitudes } & Perceptual benefits & -.05 & .607 & - & - & -.05 & .607 \\
\hline & & Perceptual barriers & .03 & .771 & - & - & .03 & .771 \\
\hline & \multirow[t]{2}{*}{ Subjective norms } & Perceptual benefits & .06 & .413 & - & - & .06 & .413 \\
\hline & & Perceptual barriers & .13 & .046 & - & - & .13 & .046 \\
\hline & \multirow{2}{*}{$\begin{array}{l}\text { Perceived behavioral } \\
\text { control }\end{array}$} & Perceptual benefits & -.13 & .042 & - & - & .13 & .042 \\
\hline & & Perceptual barriers & .09 & .034 & - & - & .09 & .034 \\
\hline & \multirow[t]{5}{*}{ Intention to stop } & Perceptual benefits & .11 & .161 & .09 & .086 & .11 & .161 \\
\hline & & Perceptual barriers & .07 & .275 & .03 & .611 & .07 & .275 \\
\hline & & Subjective attitudes & .22 & .031 & - & - & .22 & .031 \\
\hline & & Subjective norms & .38 & .004 & - & - & .38 & .004 \\
\hline & & Perceived behavioral control & .55 & .004 & - & - & .55 & .004 \\
\hline
\end{tabular}

GFI=Goodness of fit index; AGFI=Adjusted goodness of fit index; CFI=Comparative normed of fit index; SRMR=Standardized root mean square residual; TLI=Tucker-Lewis index; NFI=Normed fit index; RMSEA=Root mean square error of approximation; SMC=Squared multiple correlation.

continue caffeine intake, which can be interpreted as the subjects seeing positive impacts from subjective norms on discontinuing highly caffeinated drink consumption.

Attitudes toward cessation of high levels of caffeine intake were found to have a significant effect on the intention to stop, which supports the results of a previous study that more positive subjective attitudes were associated with greater willingness to quit smoking [29]. However, other studies [23,25,27] have shown that subjective attitudes had the strongest influence on intention, contradicting the results of this study. When attitudes and subjective norms do not match each other, an individual's intention is determined by the relative importance of the two factors. For example, attitudes are important for competitive behaviors, while norms are more im- portant for cooperative behaviors. The subjective attitudes and subjective norms analyzed in this study are not conflicting concepts; instead, ceasing caffeine intake is a cooperative behavior, making subjective norms more important in this context.

In the present study, the score for attitudes toward stopping drinking highly caffeinated beverages was 29.46 points, showing a positive attitude toward discontinuing consumption.

In this study, lower scores for perceived benefits and higher scores for perceived barriers affected perceived behavioral control. The most popular timing of caffeine intake was before and after studying, and the most popular location was the library. Since the location of highly caffeinated drink con- 
sumption was inherently linked to academics, we conclude that the college students consumed highly caffeinated drinks in anticipation of a stimulating effect that would help them concentrate on their studies. This appears to be a result of anticipating the positive effects of caffeine on mental activity (i.e., a rapid pharmacological reaction and enhanced performance through its stimulatory effects) [18]. However, the average score for perceived benefits was 2.59 out of 5 ; this mediocre result indicates that the expectations of benefits from those effects was not particularly high.

It was found that $39.3 \%$ of the participants in the present study had experienced side effects of caffeinated drink consumption, including sleep disorders, heart palpitations, skin roughness, anxiety, and others. These findings are similar to those of a previous study, which reported that sleep disorders were the most common side effect, followed by excess urination and palpitation [18]. Because caffeine is well known for its positive effects, such as promoting a clear mind and increased concentration, many people enjoy drinking highly caffeinated drinks [2-4]. However, excessive consumption of caffeine can lead to acute addiction symptoms such as poor appetite, anxiety, vomiting, and tachycardia, as well as chronic addiction symptoms such as hypersensitivity, muscle cramps, insomnia, and heart palpitations $[17,18]$.

Perceived barriers appeared to be higher than perceived benefits, as the mean score for perceived barriers was 1.87 out of 3 points. Perceived barriers do not directly or indirectly affect the intention to discontinue high levels of caffeine intake, but affect it through mediation by subjective norms. Perceived barriers also exert an effect by means of perceived behavioral control, along with perceived benefits. This is consistent with the findings of a prior study [30] suggesting that the benefits and risks associated with health threats of adolescents' high caffeine intake were the strongest predictor variables. A prior study [30] found that high caffeine drinkers were less likely to recognize the severity and likelihood of the risks of excessive caffeine intake than non-drinkers.

The subjects of this study were limited to those who consumed highly caffeinated beverages. We suggest that future studies should include subjects who do not consume highly caffeinated drinks and investigate their perceptions of susceptibility, severity, self-efficacy, and cues for behavior.

This hypothetical model built on the basis of the theory of planned behavior provides a suitable theoretical framework to explain the nature of college students' intention to stop consuming highly caffeinated drinks, as its explanatory power was relatively high. Subjective attitudes, subjective norms, and perceived behavioral control explained $45.3 \%$ of college students' intention to discontinue consumption of highly caffeinated beverages. This level of explanatory power is higher than was obtained in a Korean meta-analysis [26], which reported that attitudes, subjective norms, and perceived behavioral control had an explanatory power of $31.5 \%$, and is similar to the explanatory power $(45.0 \%)$ reported in a previous meta-analysis [23] that applied the theory of planned behavior to analyze nutrition-related health behaviors of young subjects within the age range of 18 to 29 years. Some of the model fit values in this study were somewhat low, which is assumed to result from the use of a different measurement system for the variables in Ajzen's theory of planned behavior [9] and Becker's health belief model $[13,19]$. We propose that a similar measurement system should be used in the future when selecting questionnaire items to measure study variables and that studies be carried out with a rigorous review of content validity.

This study is meaningful in that it can be used as a basic reference for developing an intervention program to promote the discontinuation of highly caffeinated drink intake by identifying factors affecting college students' intention to stop drinking highly caffeinated beverages.

In summary, subjective attitudes, subjective norms, and perceived behavioral control over the intention to cease high levels of caffeine consumption were found to affect the intention to stop, perceived benefits affected subjective norms, and perceived benefits and barriers affected behavioral control.

Therefore, in order to promote cessation of high levels of caffeine consumption among college students, it is necessary to emphasize attitudes toward discontinuing high levels of caffeine consumption, subjective norms relating to high caffeine intake, and improvements in perceived behavioral control. In particular, as behavioral control was found to be the most significant factor affecting the intention to discontinue high levels of caffeine intake, we expect that this study will be utilized to develop an intervention program to promote discontinuation of highly caffeinated drink consumption.

\section{CONCLUSION}

Based on Ajzen's theory of planned behavior and Becker's health belief model, this study confirmed that a structural equation model was appropriate for explaining university students' intention to discontinue highly caffeinated drink consumption. The most influential factor was perceived behavioral control, and other significant factors included subjective norms and subjective attitudes. While most of the past research were related to caffeinated drink consumption has only been conducted on the fact finding, but this study is meaningful in that it established causal links between factors affecting the intention based on Becker's and Ajzen's theory to discontinue highly caffeinated drinks consumption in a sam- 
ple of undergraduate students who were high caffein drinks users.

However, the limitations of this study are as follows. First, its generalizability is limited, as it does not represent all Korean university students, although subjects were selected from five geographically diverse cities and provinces. Second, it was not possible to objectively confirm heavy caffeine use because a self-reported survey was used to analyze participants' caffeine drinking patterns and perceptions of themselves as caffeine addicts. Third, we were not able to confirm whether actions were taken to stop drinking highly caffeinated drinks by the subjects who expressed an intention to do so. These limitations need to be addressed by collecting a sample that properly represents Korean college students and identifying subjects with high caffeine intake through actual measurements in future studies applying the theory of planned behavior. In addition, we suggest that further studies utilizing the extended theory of planned behaviors, including social and psychological factors related to caffeine consumption, should be conducted in the future.

\section{Conflict of interest}

No existing or potential conflict of interest relevant to this article was reported.

\section{REFERENCES}

1. Seifert SM, Schaechter JL, Hershorin ER, Lipshultz SE. Health effects of energy drinks on children, adolescents, and young adults. Pediatrics. 2011;127(3):511-528.

https://doi.org/10.1542/peds.2009-3592

2. Yoo HS, Sim KH. Survey on the high-caffeine energy drink consumption status of university students in Seoul. Journal of the East Asian Society of Dietary Life. 2014;24(3):405-420.

https://doi.org/10.17495/easd1.2014.06.24.3.407

3. Malinauskas BM, Aeby VG, Overton RF, Carpenter-Aeby T, Barber-Heidal K. A survey of energy drink consumption patterns among college students. Nutrition Journal. 2007;6(1):35.

4. Steinke L, Lanfear DE, Dhanapal V, Kalus JS. Effect of "energy drink" consumption on hemodynamic and electrocardiographic parameters in healthy young adults. Annals of Pharmacotherapy. 2009;43(4):596-602. https://doi.org/10.1345/aph.1L614

5. Korea Consumer Agency. Survey on safety of energy drinks. Safety Report. Eumseong: Korea Consumer Agency; 2013 November. p. 9-63.

6. Reissig CJ, Strain EC, Griffiths RR. Caffeinated energy drinks-A growing problem. Drug and Alcohol Depend. 2009;99(1-3):1-10. https://doi.org/10.1016/j.drugalcdep.2008.08.001

7. Ali F, Rehman H, Babayan Z, Stapleton D, Joshi DD. Energy drinks and their adverse health effects: A systematic review of the current evidence. Postgraduate Medicine. 2015;127(3):308-322.

https://doi.org/10.1080/00325481.2015.1001712

8. Ministry of Food and Drug Safety. Safe levels of caffeine intake in Korea-evaluation results of caffeine intake [Internet]. Cheongju: Ministry of Food and Drug Safety; 2015 [cited 2020 January 8]. Available from:

https://www.kca.go.kr/home/sub.do?menukey=4062\&mode= view\&no=1001450750\&searchKeyword=에너지

9. Ajzen I. The theory of planned behavior. Organizational Behavior and Human Decision Processes. 1991;50(2):179-211.

https://doi.org/10.1016/0749-5978(91)90020-T

10. Rath M. Energy drinks: What is all the hype? The dangers of energy drink consumption. Journal of the American Academy of Nurse Practitioners. 2012;24(2):70-76. https://doi.org/10.1111/j.1745-7599.2011.00689.x

11. Bitancourt T, Tissot MC, Fidalgo TM, Galduróz JC, da Silveira Filho DX. Factors associated with illicit drugs' lifetime and frequent/heavy use among students results from a population survey. Psychiatry Research. 2016;237:290-295.

https://doi.org/10.1016/j.psychres.2016.01.026

12. Kim IK, Kim KM. Energy drink consumption patterns and associated factors among nursing students: A descriptive survey study. Journal of Addictions Nursing. 2015;26(1):24-31. https://doi.org/10.1097/JAN.0000000000000061

13. Becker MH. The health belief model and sick role behavior. Health Education Monographs. 1974;2(4):409-419. https://doi.org/10.1177/109019817400200407

14. Didarloo A, Nabilou B, Khalkhali HR. Psychosocial predictors of breast self-examination behavior among female students: An application of the health belief model using logistic regression. BMC Public Health. 2017;17(1):861. https://doi.org/10.1186/s12889-017-4880-9

15. Son KM, Kim YH, Park SR. The relationships between transtheoretical model and health belief model to explain exercise behavior. The Korean Journal of Physical Education. 2009;48(6): 163-173.

16. Park JS, Lee EJ, Lee CY, Jung HS. Consumption status, risk awareness and experience of adverse effects of high-caffeine energy drink among university students. Journal of Korean Public Health Nursing. 2015;29(1):102-114.

17. Park S, Lee Y, Lee JH. Association between energy drink intake, sleep, stress, and suicidality in Korean adolescents: Energy drink use in isolation or in combination with junk food consumption. Nutrition Journal. 2016;15(1):87.

18. Lee BH, Park YS, Kim JS, Yoo JH, Lee JK. Caffeine consumption and its related symptoms in university students. Journal of the Korean Academy of Family Medicine. 2007;28(1):9-16.

19. Woo J. The concept and understanding of structural equation model. Seoul: Hannarae; 2012. p. 275-361. 
20. Hair JF, Black B, Babin B, Anderson RE, Tatham RL. Multivariate data analysis. 6th ed. London: Pearson; 2005. p. 49-74.

21. Mcllvain GE, Noland MP, Bickel R. Caffeine consumption patterns and beliefs of college freshmen. American Journal of Health Education. 2011;42(4):235-244.

https://doi.org/10.1080/19325037.2011.10599193

22. Kang H. Discussions on the suitable interpretation of model fit indices and the strategies to fit model in structural equation modeling. Journal of the Korean Data Analysis Society. 2013;15(2):653668.

23. McDermott MS, Oliver M, Simnadis T, Beck EJ, Coltman T, Iverson $\mathrm{D}$, et al. The theory of planned behaviour and dietary patterns: A systematic review and meta-analysis. Preventive Medicine. 2015; 81:150-156. https://doi.org/10.1016/j.ypmed.2015.08.020

24. Kassem NO, Lee JW, Modeste NN, Johnston PK. Understanding soft drink consumption among female adolescents using the theory of planned behavior. Health Education Research. 2003;18(3): 278-291. https://doi.org/10.1093/her/cyf017

25. Hagger MS, Chan DK, Protogerou C, Chatzisarantis NL. Using meta-analytic path analysis to test theoretical predictions in health behavior: An illustration based on meta-analyses of the theory of planned behavior. Preventive Medicine. 2016;89:154-161. https://doi.org/10.1016/j.ypmed.2016.05.020

26. Sohn Y, Lee B. An efficacy of social cognitive behavior model based on the theory of planned behavior: A meta-analytic review. Korean Journal of Journalism and Communication Studies. 2012;56(6): 127-161.

27. Cooke R, Dahdah M, Norman P, French DP. How well does the theory of planned behaviour predict alcohol consumption? A systematic review and meta-analysis. Health Psychology Review. 2016;10(2):148-167.

https://doi.org/10.1080/17437199.2014.947547

28. Armitage CJ, Conner M. Efficacy of the theory of planned behaviour: A meta analytic review. British Journal of Social Psychology. 2001;40(4):471-499. https://doi.org/10.1348/014466601164939

29. Do ES, Choi E. Structural equation modeling on smoking cessation intention in male technical high school students. Journal of Korean Academy of Nursing. 2017;47(2):211-221. https://doi.org/10.4040/jkan.2017.47.2.211

30. Ha D, Song I, Jang G, Lee EK, Shin JY. Use pattern and predictors of use of highly caffeinated energy drinks among South Korean adolescents: A study using the health belief model. BMJ Open. 2017;7(9):e017224. https://doi.org/10.1136/bmjopen-2017-017224 